\title{
How to Design Experiments in Animal Behaviour
}

\author{
2. Do Bees Have Colour Vision?
}

\section{Raghavendra Gadagkar}

In the second article in the series, I will describe how the young Karl von Frisch, later to become another founding father of ethology and Nobel Laureate, defied established authority to design simple yet logically clever experiments to show that honey bees indeed have colour vision. His experiments forever changed our view of animals and also the way experiments in animal behaviour are designed. It might interest readers to know that Karl von Frisch's experiments described in this part inspired Tinbergen's experiments described in the previous article in this series ${ }^{1}$.

\section{The Ability to Ask Questions}

Children are born with a natural curiosity and incessantly ask questions, much to the irritation of their parents and teachers. Both parents and especially teachers work overtime to kill this curiosity; indeed, our entire system of child rearing and education are willy-nilly designed to abolish curiosity. We force children to shift their focus from questions to answers. We associate social prestige with knowing answers and shame with not knowing them. We leave no room for pride in asking questions and no shame in not doing so. That is the reason why our students don't ask questions in the classroom, and when pressed to say why they did not ask even though they did not know the answers, the standard reply is that they thought it might be a stupid question, meaning the answer is already known to someone. A child (before education, if we can still find any) does not share this definition of a stupid question. My repeated assertions in the classroom that no question can be stupid by definition, and that

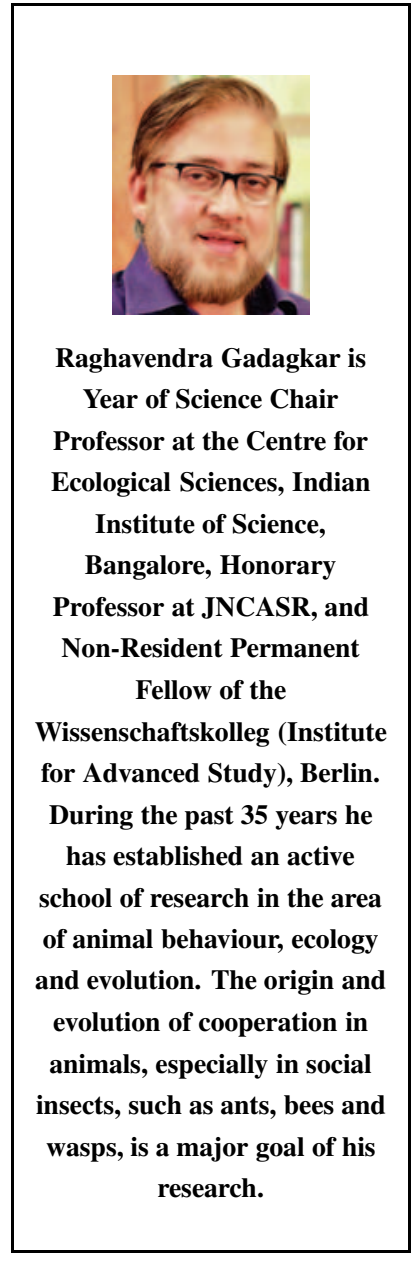

${ }^{1}$ See $\mathrm{R}$ Gadagkar, How to Design Experiments in Animal Behaviour 1. How Wasps Find Their Nests, Resonance, Vol.23, No.8, pp.871884, 2018. 
Figure 1. Karl von Frisch (1886-1982, Nobel Laureate, 1973).

\section{Keywords}

Ethology, honey bees, colour vision, learning, experimental design.

Why are flowers brightly coloured? The logical deduction is that flowers must be brightly coloured in order to attract bees.

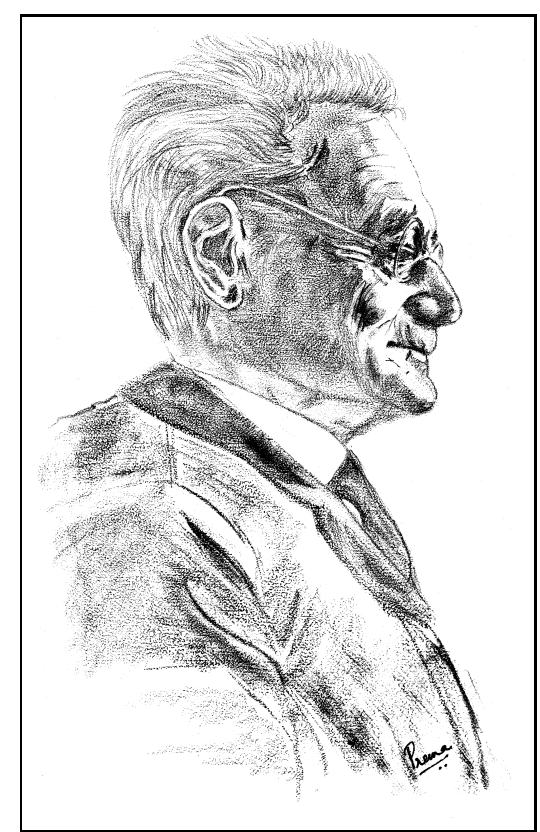

only answers can be stupid, are often met with a polite, unconvinced smile! If there is indeed such a thing as a stupid question, it is one that is in principle, unanswerable, certainly not one that is answerable, and most certainly not one that has already been answered.

\section{Karl von Frisch's Question}

Karl von Frisch (Figure 1), Nobel laureate, another founding father of ethology, and one of the two protagonists of this second instalment of the series on how to design experiments in animal behaviour (the other protagonist being the honey bee) asked a simple question: why are flowers brightly coloured? He surmised that flowers must be brightly coloured in order to attract bees. But this was counter to the view prevailing at that time because one of the most distinguished scientist of the time and an authority in visual science, the ophthalmologist $\mathrm{C}$ von Hess (indeed Sir von Hess), had concluded on the basis of his own experiments, that all invertebrates including honey bees and even fish 
were colour blind. For von Frisch, the logical deduction that flowers must be brightly coloured to attract honey bees and that bees must, therefore, have colour vision, was so compelling that he was unimpressed by the authority of Sir von Hess and decided to ignore established knowledge and conduct his own experiments to re-examine the question of colour vision in honey bees. Recall "courage in framing expectations" as one of the descriptors of ethology, which I quoted from A Philosophical Dictionary of Biology by Peter and Jeanne Medawar, in the first article of this series. In 1949, Donald Griffin, famous for his discovery of echolocation in bats, then at Cornell University, USA, arranged for von Frisch to tour the USA and give a series of lectures. These lectures were subsequently published by Cornell University Press in the form of a highly readable little book entitled Bees: Their Vision, Chemical Senses and Language [1]. This permits us to hear it from the horse's mouth: “....von Hess asserted, fishes and invertebrates, and in particular bees, are totally color-blind. If this were true, the colors of flowers would have no biological significance. But I could not believe it, and my scepticism was the first motive which led me to begin my studies of bees about 1910. I tried to find out whether bees have a color sense" [1].

\section{The Experiments}

Although von Frisch worked on many animals during his lifetime including fish, honey bees were his most favourite study objects. It is useful to contrast the experimental designs of von Hess on the one hand and those of von Frisch on the other. Von Hess's paper in German remains untranslated into English, and we have to, therefore, depend on other scientists who have described his experiments. Bert Hölldobler, a renowned authority on ants and who, along with Martin Lindauer (his PhD supervisor and a student of von Frisch), edited a volume in memory of von Frisch [2], gives us the essence of von Hess's error: "Von Hess placed honey bee workers into experimental chambers, where environmental factors could be controlled, and presented them with two light spots simultaneously, each of a different colour and varying in
Von Hess placed honey bee workers into experimental chambers, where environmental factors could be controlled, and presented them with two light spots simultaneously, each of a different colour and varying in light intensity. The bees were invariably attracted to the brightest spot, whatever the colour was, which seemed to prove that bees are colour blind. 
Von Frisch ensured that he trained and tested his bees in their natural habitat. He tested them in a situation where they would be expected to be motivated to learn and to display their ability to distinguish different colours if they have the capability to do so.

In addition to their simplicity and originality, von Frisch's experiments gave birth to a whole new field of

study. Also, these

experiments are so simple that they have been repeated countless times not only to confirm von Frisch's original results but also to test the sensory and learning abilities of many animals under many different conditions. light intensity. In this situation, the bees were invariably attracted to the brightest spot, whatever the colour was, which seemed to prove [to von Hess] that bees are colour blind and react only to different light intensities" [2].

In contrast, von Frisch ensured that he trained and tested his bees in their natural habitat. He tested them in a situation where they would be expected to be motivated to learn and to display their ability to distinguish different colours if they have the capability to do so. Ironically, von Frisch's experiment was much simpler than that of von Hess's. His experiment was as simple as his description of it. Let's listen to him again: "By the scent of a little honey it is possible to attract bees to an experimental table. Here, we can feed them on a piece of blue cardboard, for example. They suck up the food and, after carrying it back to the hive, give it to the other bees. The bees return again and again to the rich source of food which they have discovered. We let them do so for some time, and then we take away the blue card scented with honey and, put out two new, clean pieces of cardboard at the site of the former feeding place - on the left a blue card and on the right a red one. If the bees remember that they found food on blue, and if they are able to distinguish between red and blue, they should now alight on the blue card. This is exactly what happens" [1].

In addition to their simplicity and originality, von Frisch's experiments gave birth to a whole new field of study. Hölldobler says "Experimental behavioural ecology can be said to have begun around 1911, when the young KARL VON FRISCH wondered why flowers are colourful" [2]. But it is their simplicity that I wish to dwell on some more here. Indeed, they are so simple that they have been repeated countless times not only to confirm von Frisch's original results but also to test the sensory and learning abilities of many animals under many different conditions. Indeed, von Frisch's experiments are a great way to train young students in designing experiments and to get them hooked to science, a much better way than merely lecturing to them in the classroom. This I can testify from personal experience.

Tenth class students in the Kendriya Vidyalaya (Central School) 
attached to my Institute are required to do a science project for one month in their vacation. Some of them come to my lab, and I get them to repeat von Frisch's experiment, which they do so with great enthusiasm and success. We have adapted von Frisch's experimental design to be able to work on the terrace of my laboratory with little danger of being stung by bees. We have designed a cardboard box in which we hide a bottle of sugar solution. The box has only two openings through which the bees can potentially enter to reach the sugar solution. At one of the entrances we place a blue cardboard disc, and at the other we place a green cardboard disc (Figure 2). During the training period, we keep only one of the discs, say the blue one open and the other (green) closed. Because the bees can enter through the blue discs and get to the sugar solution successfully, we refer to 'blue as plus (+)' and because they cannot do so through the green disc we refer to 'green as minus (-)'. Following von Frisch, we train bees from a nearby hive which we maintain, to come to our feeding station rather than go to nearby real flowers. This we accomplish by adjusting the concentration of the sugar solution, to compete with the varying attractiveness of the surrounding flora. If our sugar solution is weak compared to the competition, the bees will abandon us and go elsewhere; if it is too strong, we may get too many bees. Indeed, we can get just the number of bees we want by carefully modulating the concentration of our sugar solution.

First, we place our sugar solution (feeder) close to the bee hive so that the bees find it accidentally. Then, when they are hooked, we gradually move the feeder closer to our desired place and finally into the cardboard box. I must say that such a procedure can achieve remarkable results. With care and persistence, bees can be lured to fly several kilometres, go around trees and buildings and even enter your lab through the window and alight on your microscope stage! In the current experiment, however, we only needed the bees to fly a few hundred meters and reach our feeder hidden inside the cardboard box. On reaching the target site, the bees quickly discover that they can enter through the openings provided. In one experiment for example, we kept the
With care and persistence, bees can be lured to fly several kilometres, go around trees and buildings and even enter your lab through the window and alight on your microscope stage! 
Figure 2. Cardboard box with blue and green discs used to train and test honey bees.Photo courtesy: Aniruddha Mitra

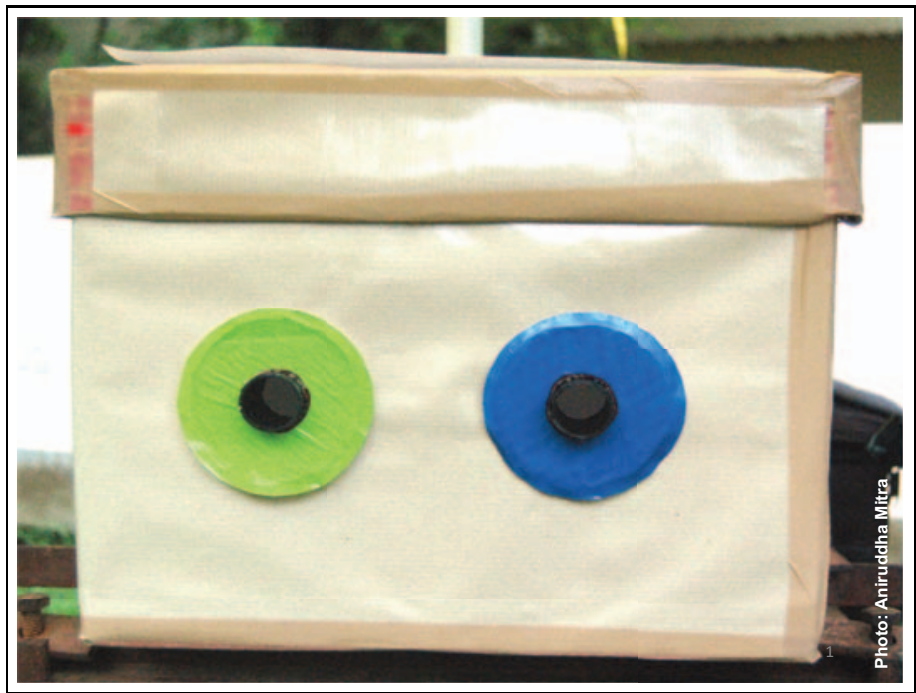

opening with the blue disc open and the opening with the green disc closed: 'blue (+) and green (-)'. Bees entered the cardboard box through the blue disc and drank the sugar solution. A great advantage of working with honey bees (of course, these are workers who do all the foraging, not the queen nor the drones) is that they are perpetually hungry as they do not immediately ingest the sugar solution all by themselves but deliver it to the waiting unloader bees back home and return for more. In fact, they also recruit more forager bees to help them transport the sugar we provide if it is attractive enough. Following several entries by the bees through the blue disc, we were ready to test them. For the test, we removed both discs and replaced them with similar fresh discs so that the bees didn't use the smell they might have left on the discs during training. Now we closed both the discs and counted the number of times they searched at the blue and green discs respectively.

The results of one of the experiments by my students is shown in Figure 3. The upper panel represents the experiment with blue $(+)$ and green (-), as described above. If the bees have learnt that the blue disc rather than the green gives them the reward of sugar solution, and if they can discriminate between the colours blue 


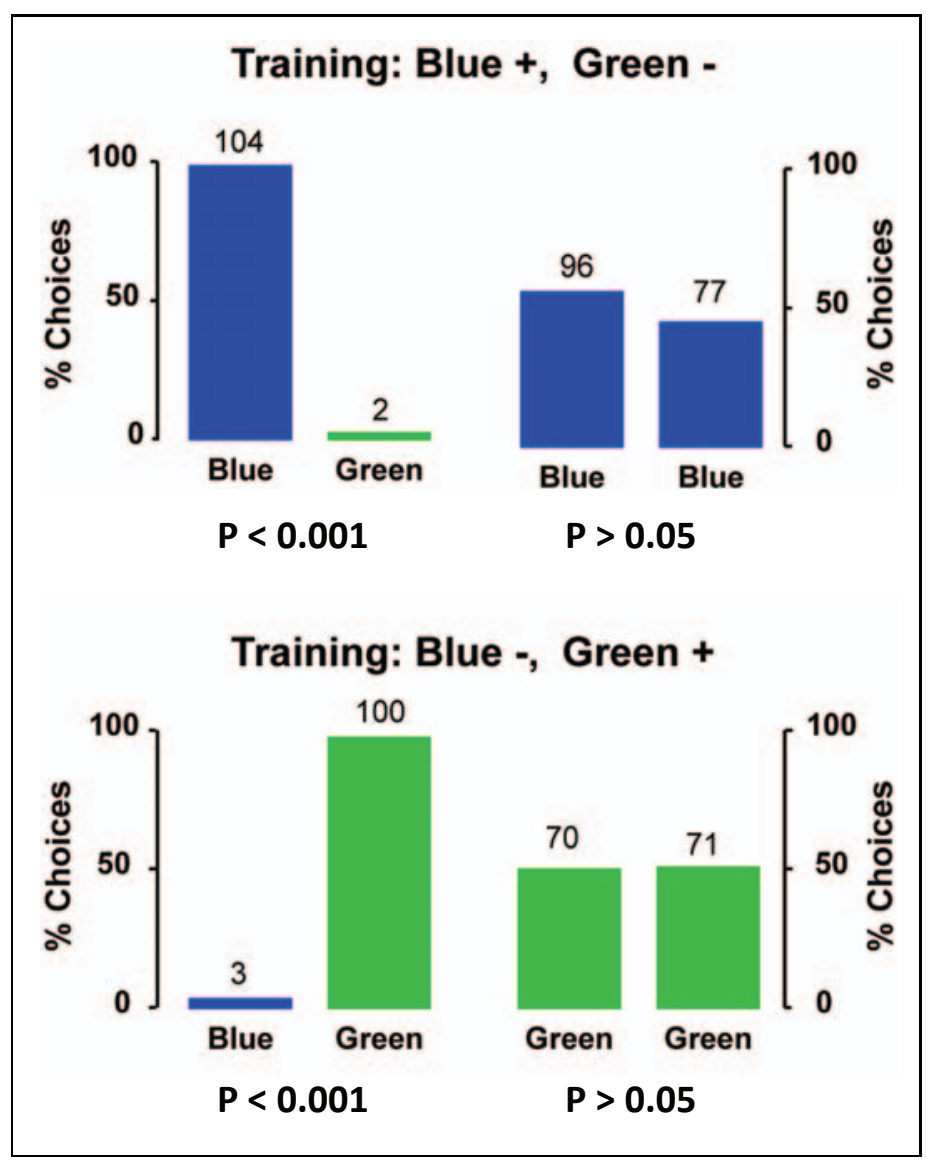

and green, they should search at the blue rather than the green disc during the test phase when both discs are closed. As you will see from the bar chart at the left of the upper panel in Figure 3, the bees searched 104 times at the blue disc and only twice at the green disc. Note that this is the sum total of searches by several bees and we have not here provided data for individual bees. The difference between 194 and 2 is quite obvious. Nevertheless, we can perform a statistical test, such as a chi-squared test, for example, to ascertain that the higher number of searches at the blue disc is not simply by chance. Such a test may be critically important if the numbers are less drastically different than the ones obtained here. In this case the ' $\mathrm{P}<0.001$ ' indicated at the bottom of the bar chart means that such a large difference as that between
Figure 3. Results of experiments designed to assess colour discrimination by honey bees. See text for a detailed description. 
We know from experience that bees are very good learners and that they will learn anything that is different between the two discs, not just their colours.
104 and 2 could have been obtained by mere chance, less often than 1 in 1000 trials, i.e., if the bees had actually not learned anything and were simply going to the blue and green discs randomly. Does this mean that we can safely conclude that the bees have indeed learned that blue is the rewarding colour and green is not? Now, remember another descriptor of ethology in the quote from Peter and Jeanne Medawar's book - "caution in coming to conclusions".

We must exercise abundant caution before concluding from this experiment that bees have learned blue versus green, let alone that they have colour vision. We know from experience that bees are very good learners and that they will learn anything that is different between the two discs, not just their colours. In this case, they might have learned, for example, that the disc on the left is rewarding and the one on the right is not rewarding. To rule out this possibility, the bees are tested repeatedly by placing closed blue discs on both sides and counting the numbers of times they search at the left and right blue discs respectively. The results plotted in the bar chart on the right side of the upper panel in Figure 3, show that the bees chose the blue disc on the left side 96 times and the blue disc on the right side 77 times. 96 is not sufficiently greater than 77 , and such a difference could have been obtained by chance alone, i.e, without the bees having learned that left is better than right. This is indicated by a similar statistical test with the result ' $\mathrm{P}>0.05$ ', meaning that there is a more than $5 \%$ probability that this is a chance event. There is much more than $5 \%$ probability in this case, but $5 \%$ is used as a cut-off so that we do not take anything seriously if there is more than $5 \%$ probability that it could have been obtained by chance alone. So, the bees have not merely learned left versus right but have learned blue versus green.

Can we conclude that the bees go preferentially to the blue disc because they have learned that blue is rewarding, and green isn't? What if the bees simply like blue and hate green? In that case, they would go the blue disc irrespective of the reward. So, my students repeated the experiment, this time making green reward- 
ing and blue unrewarding. The results show that the bees trained with green positive choose green over blue, and once again not as left versus right (see bottom panel of Figure 3). Thus, when rewarded at blue, the bees choose blue and when rewarded at green they choose green. Can we finally conclude that bees have colour vision? Not quite yet, I am afraid. Von Frisch realized of course that such experiments merely demonstrate that bees can distinguish the blue and green discs from each other but this doesn't necessarily prove true colour vision. Even a colour-blind person can tell the two discs apart, just as we can tell them apart on a black and white photograph because the two discs appear as two different shades of grey. To rule out the possibility that his bees were merely distinguishing colours as different shades of grey, von Frisch performed yet another experiment. This time he trained the bees to distinguish blue colour from several shades of grey, ranging from black to white. When offered a choice between blue and different shades of grey, the bees correctly chose blue over all the other offerings. Only then did von Frisch conclude that bees have colour vision.

\section{Happy Ending}

There was a happy ending to this story but not before some more hiccups. Professor Lars Chittka, of the Queen Mary University in London, an expert in colour vision and learning abilities in honey bees and bumble bees, describes vividly the drama that followed, in his forthcoming book The Mind of the Bee: “.....von Hess was infuriated - having caught wind of the young scientist's experiments, he rushed to publish his own account before von Frisch could even get his work into print.....his paper was entitled 'Experimental investigations about the alleged color sense of honey bees'; in it, he blustered (in 1913): "It was possible to demonstrate that the older claims of Lubbock...., as well as recent ones of von Frisch, according to which bees can be "trained" to certain colors, are wrong altogether....not a single fact is known that could even make plausible the notion of a color sense in bees....through my investigations, this assumption is terminally
To rule out the possibility that the bees go preferentially to the blue disc because they have learned that blue is rewarding, and green isn't, the bees are tested repeatedly by placing closed blue discs on both sides and counting the numbers of times they search at the left and right blue discs respectively. 
refuted." [3]. Although von Frisch put up a brave front to the world, Chittka quotes from a moving letter that von Frisch wrote to his mother saying, "I have the uncomfortable feeling that I now have a real enemy in the world out there, the first one, and someone who could really damage me" [3]. There was more drama to come as von Frisch was targeted by the Nazis because his grandmother was of Jewish origin, but he was just about spared (actually his incarceration was merely planned to be postponed until the Germans won the war!) because his knowledge of honey bees was suspected to be of use in the war effort. Read more about the interplay between science, society and politics in Chittka's forthcoming book [3]. In the end, however, the world came to accept von Frisch's clear-cut experimental evidence, so that von Hess was all but forgotten and von Frisch was awarded the Nobel Prize.

\section{Bees Have Trichromatic Colour Vision}

Not only did von Frisch's evidence from behavioural evidence show without doubt that bees have colour vision, but subsequent experiments by von Frisch and others showed that honey bee colour vision is quite different from that of humans, and that bees are blind to red colour.
Not only did von Frisch's evidence from behavioural evidence show without doubt that bees have colour vision, but subsequent experiments by von Frisch and others showed that honey bee colour vision is quite different from that of humans, and that bees are blind to red colour. Many years later, von Frisch's successor in the University of Munich, the physiologist H Autrum obtained direct evidence of (trichromatic) colour vision in bees in 1962 by inserting microelectrodes into single photoreceptor cells in the bees' eyes and recorded their electrical signals in response to lights of different wavelengths. It was the first time that such a feat was accomplished in any animal. The spectral sensitivities of receptors in humans and honey bees are shown in Figure 4. While humans recognise three primary colours - red, blue and green, bees also recognise three primary colours, but these are ultraviolet, blue and green. Thus, the visible spectrum of bees is a bit shifted from that of human beings so that bees cannot see as far into the red as we humans and we cannot see UV. This has interesting consequences for our (in)ability to judge what the bees can see. When photographed with a UV filter, we can visualize 
that bees can see remarkable patterns on flowers some of which guide the bees straight to the pollen-bearing anthers, something to which we are blind. James L Gould said it beautifully once of Karl von Frisch: "His pioneering work inspired the discovery of several otherwise unimaginable sensory systems in animals: infrared detectors in night-hunting snakes, ultrasonic sonar in dolphins and bats, infrasonic hearing in birds, and magnetic field sensitivity in a variety of animals. Doubtless, other systems are still to be discovered. The lesson is a melancholy one: We are blind to our own blindness, and must not try to read our own disabilities into the rest of animal kingdom". Autrum's expensive and sophisticated recordings of the spectral sensitivities of the honey bee receptors are correctly regarded as the direct and final proof of honey bee colour vision, but it is von Frisch and his simple behavioural experiments that are correctly credited with the original discovery that bees have colour vision. As Professor Chittka has perceptively remarked, "....one should not fetishize technology many of today's academics, and many journal editors and funding agencies, confuse using fancy (and often expensive) technology for entirely predictable outcomes with the process of scientific discovery. To this date, many of the most important discoveries in biology are made with careful observation and the simplest experimental tools imaginable, while armies of scientists equipped with fashionable 'omics' tools confirm decades-old knowledge with novel methods, with marginal gains in terms of pushing the boundaries of science" [3].

\section{Why do Bees Have Colour Vision?}

Karl von Frisch asked the obvious question as to why flowers are brightly coloured and proposed the obvious hypothesis that it must be to attract honey bees, which implied that bees must have colour vision. As we have seen, he then set out to prove this hypothesis. Conversely, we can ask why bees have colour vision and hypothesize that it must be to locate flowers efficiently and harvest pollen and nectar. The idea that colour vision in bees and
"To this date, many of the most important discoveries in biology are made with careful observation and the simplest experimental tools imaginable, while armies of scientists equipped with fashionable 'omics' tools confirm decades-old knowledge with novel methods, with marginal gains in terms of pushing the boundaries of science." 
Figure 4. Spectral sensitivity curves of humans (top) and bees (bottom). (modified from images kindly provided by Professor Lars Chittka).

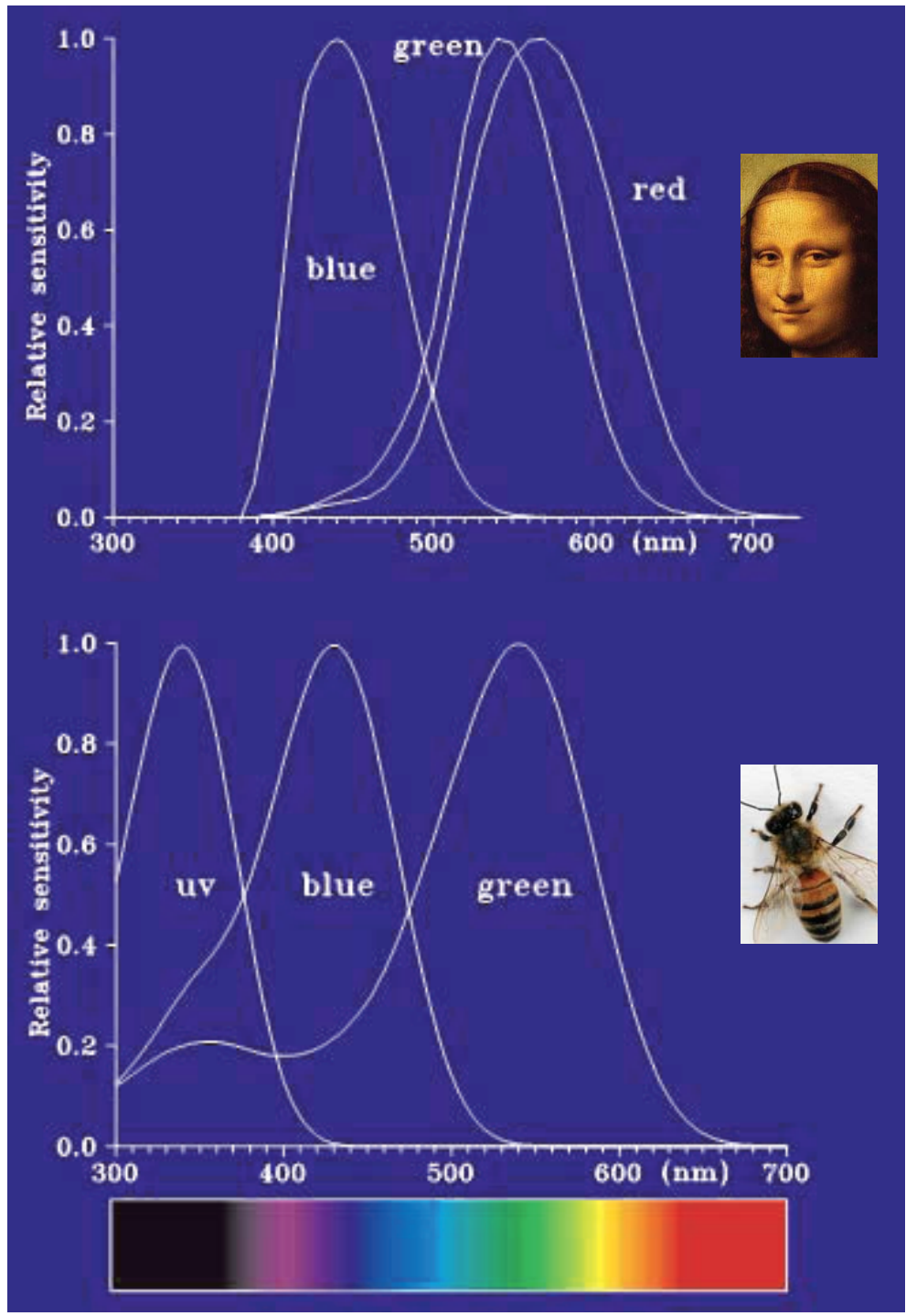

brightly coloured flowers coevolved, reinforcing each other, making bees with better colour vision better at seeking out flowers and brightly coloured flowers better at attracting bees - a win-win situation - is indeed an attractive one. Research by Professor Lars Chittka has shown us that an attractive hypothesis is not necessarily a correct one [5]. By mapping the spectral sensitivities of the photoreceptors of different insects onto a phylogenetic tree of 


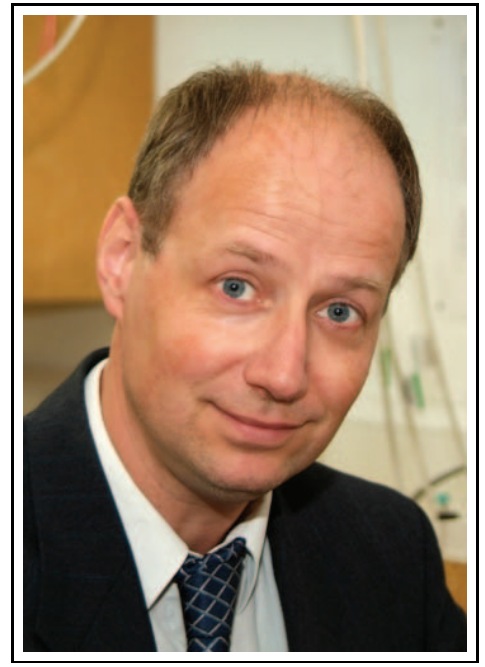

arthropods, he has shown that the spectral sensitivities of arthropod lineages that diverged from those of bees even before flowers had evolved are very similar to those of bees. In other words, bees had evolved their trichromatic colour vision even before flowers evolved. Thus, bees do not have colour vision to find flowers; instead, flowers seem to have evolved colours to match the spectral sensitivities of bees. And why bees evolved colour vision in the absence of flowers is a mystery that is waiting to be solved - take note, readers! You can read more about the evolution of colour vision in insects in a review article by Briscoe and Chittka [5].

\section{Reflections}

There are many takeaways from all that we have seen so far from Karl von Frisch's experiments and those that followed. The spotlight is on simple experiments, clever experimental designs, courage in framing expectations, caution while coming to conclusions, disrespect for authority, and not being enamoured by attractive hypotheses. I also emphasized in the first article in this series that readers should not only reflect on the design of the experiments being discussed but also attempt to design, and if possible, perform their own experiments, swapping animals, questions and
Figure 5. Prof. Lars Chittka (1963-), Queen Mary University, London.

bees do not have colour vision to find flowers; instead, flowers seem to have evolved colours to match the spectral sensitivities of bees. And why bees evolved colour vision in the absence of flowers is a mystery that is waiting to be solved! 
Figure 6. Contextdependent learning and recall. Bees can learn to choose one colour while entering the feeder and a different colour while entering their hives. See text for details.

Figure 7. Bees can associate with different colours at different times of the day. See text for details.
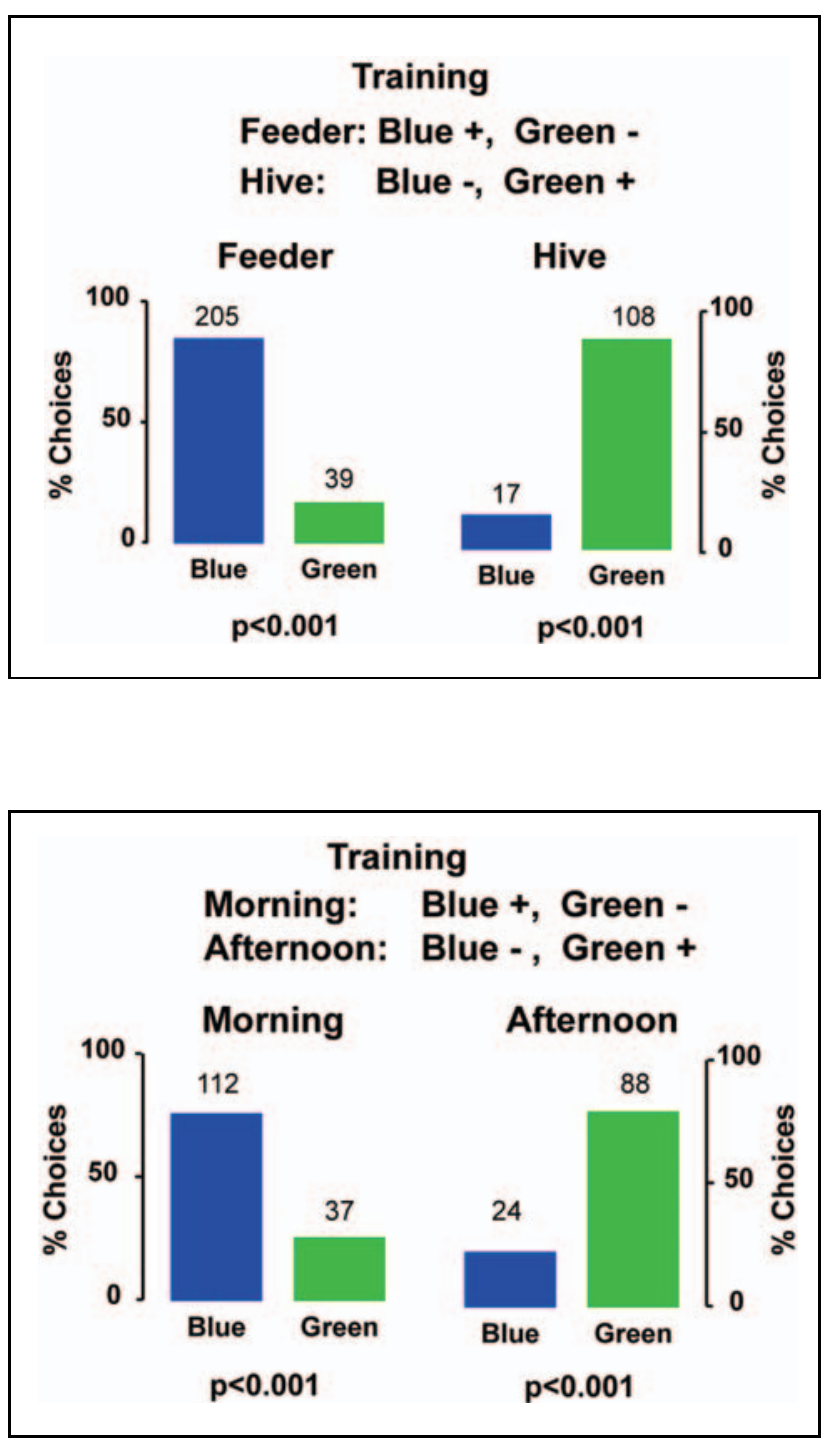

methods as need be. Here, I have the opportunity to demonstrate how this can indeed be done. My high school students showed the way. They have replaced coloured discs with pairs of discs with contrasting patterns, for example, a black circle on one disc and a black square or rectangle on the other, vertical stripes on one disc and horizontal stripes on the other, and have shown that the bees can efficiently learn the differences in patterns and shapes. In some years they decided to test the limits of the learning abil- 
ities of the bees. This experiment was performed in my laboratory when Professor M V Srinivasan, then at the Australian National University, Canberra, was visiting me (you will hear more about him in a future article in this series). In one experiment they placed the bee hive also in a cardboard box with two openings surrounded by blue and green discs. The hive, so enclosed in a cardboard box was placed only a few meters from the feeder which was, as before, enclosed in a cardboard box with blue and green discs. The bees were trained to fly back and forth between their hive and feeder. Students being mischievous by nature, decided to trick the bees. At the feeder they kept the blue open and green closed while at the hive they kept the blue closed and green open. The challenge for the bees was to choose blue over the green at the feeder and within a few seconds, choose green over blue at the hive entrance. Do bees have the ability to learn and recall the correct colours in such a context-specific manner, and that too in rapid succession? On another occasion, they enclosed only the feeder in the cardboard box with blue and green discs but kept the blue disc open and green disc closed in the morning and the blue disc closed and green disc open in the afternoon. The challenge was that the same bees which were successfully choosing blue over the green in the morning should reverse their preferences at the same feeder in the afternoon. Do bees have the ability to associate their preferences with the time of the day and make a choice after consulting their biological clocks? In both cases, the bees came out with flying colours! They can learn and recall both in a context-specific manner as we as in a timedependent manner (Figures 6 and 7). This associative learning paradigm in which the bees associate something (colour in this case) with a reward, first perfected by Karl von Frisch, has since been used thousands of times and is of boundless utility. Finally, I think you will agree that, as promised in the first article in this series, I have indeed restored the glory of the honey bees!
Do bees have the ability to associate their preferences with the time of the day and make a choice after consulting their biological clocks? In both cases, the bees came out with flying colours! They can learn and recall both in a context-specific manner as we as in a time-dependent manner. 


\section{Suggested Reading}

[1] Karl von Frisch, Bees: Their Vision, Chemical Senses and Language, Cornell University Press, Ithaca, NY, USA and London, 1971, 1950.

Address for Correspondence

Raghavendra Gadagkar

Centre for Ecological Sciences

Indian Institute of Science

Bangalore 560 012, India.

Email: ragh@iisc.ac.in

[2] B Hölldobler and M Lindauer, Experimental Behavioural Ecology and Sociobiology - in Memoriam Karl von Frisch, Gustav Fischer Verlag, Stuttgart, New York, 1985.

[3] Lars Chittka, The Mind of The Bee, Princeton University Press, 2019 (in press).

[4] Lars Chittka, Does Bee Color Vision Predate the Evolution of Flower Color? Naturwissenschaften, Vol.83, pp.136-138, 1996.

[5] A D Briscoe and L Chittka, The Evolution of Color Vision in Insects, Ann. Rev. Entomol., Vol.46, pp.471-510, 2001. 